\title{
Release of cell wall phenolic esters during hydrothermal pretreatment of rice husk and rice straw
}

\author{
Jia Wu' ${ }^{1}$, Samuel R. A. Collins ${ }^{1}$, Adam Elliston ${ }^{1}$, Nikolaus Wellner², Jo Dicks ${ }^{3}$, lan N. Roberts ${ }^{3}$ \\ and Keith W. Waldron ${ }^{1 *}$ (B)
}

\begin{abstract}
Background: Rice husk and rice straw represent promising sources of biomass for production of renewable fuels and chemicals. For efficient utilisation, lignocellulosic components must first be pretreated to enable efficient enzymatic saccharification and subsequent fermentation. Existing pretreatments create breakdown products such as sugarderived furans, and lignin-derived phenolics that inhibit enzymes and fermenting organisms. Alkali pretreatments have also been shown to release significant levels of simple, free phenolics such as ferulic acid that are normally esterified to cell wall polysaccharides in the intact plant. These phenolics have recently been found to have considerable inhibitory properties. The aim of this research has been to establish the extent to which such free phenolic acids are also released during hydrothermal pretreatment of rice straw (RS) and rice husk (RH).
\end{abstract}

Results: RS and RH were subjected to hydrothermal pretreatments over a wide range of severities (1.57-5.45). FTIR analysis showed that the pretreatments hydrolysed and solubilised hemicellulosic moieties, leading to an enrichment of lignin and crystalline cellulose in the insoluble residue. The residues also lost the capacity for UV autofluorescence at $\mathrm{pH} 7$ or $\mathrm{pH} 10$, indicating the breakdown or release of cell wall phenolics. Saponification of raw RS and RH enabled identification and quantification of substantial levels of simple phenolics including ferulic acid (tFA), coumaric acid (pCA) and several diferulic acids (DiFAs) including 8-O-4'-DiFA, 8,5'-DiFA and 5,5'-DiFA. RH had higher levels of pCA and lower levels of tFA and DiFAs compared with RS. Assessment of the pretreatment liquors revealed that pretreatment-liberated phenolics present were not free but remained as phenolic esters (at $\mathrm{mM}$ concentrations) that could be readily freed by saponification. Many were lost, presumably through degradation, at the higher severities.

Conclusion: Differences in lignin, tFA, DiFAs and pCA between RS and RH reflect differences in cell wall physiology, and probably contribute to the higher recalcitrance of RH compared with RS. Hydrothermal pretreatments, unlike alkali pretreatments, release cinnamic acid components as esters. The potential for pretreatment-liberated phenolic esters to be inhibitory to fermenting microorganisms is not known. However, the present study shows that they are found at concentrations that could be significantly inhibitory if released as free forms by enzyme activity.

Keywords: Lignocellulosic biomass, Rice husk, Rice straw, Pretreatment, Inhibitors, Bio-ethanol, Phenolic esters, Ferulic acid, Di-ferulic acid

\footnotetext{
${ }^{*}$ Correspondence: keithwwaldron@outlook.com

${ }^{1}$ The Biorefinery Centre, Quadram Institute Bioscience, Norwich Research

Park, Colney, Norwich NR4 7UA, UK

Full list of author information is available at the end of the article
} 


\section{Background}

Efficient enzymatic saccharification of lignocellulose requires pretreatment to enhance the accessibility of cellulose by cellulases $[1,2]$. Pretreatments can break down cell wall bonds and loosen the cell wall polymer network [3]. Many of these processes result in the production and solubilisation of inhibitors to enzymolysis and fermentation $[4,5]$. High temperatures create furan-containing moieties such as hydroxy-methyl furfural (5HMF) and furfural (2FA) from the carbohydrate components [6]. Acid, alkali and high temperatures also result in the release of many phenolics, including those derived from lignin, which can inhibit cellulases and xylanases [7-9], and cinnamic acid esters, released from hemicelluloses such as arabinoxylans that have antimicrobial activity [10]. Whilst much research has been carried out on furans and lignin-derived phenolics, the important roles of such cinnamic acid derivatives as microbial inhibitors have been highlighted only recently. Several studies have explored the potential to enhance the capability of fermenting microorganisms such as yeasts and bacteria to metabolise such phenolics $[11,12]$. Sato and colleagues [13] have developed Saccharomyces cerevisiae using a forced evolutionary approach to increase tolerance to pCA and tFA inhibitors.

Rice straw (RS) and rice husk (RH) are globally important lignocellulosic feedstocks, particularly in China and Asian countries. Alkali pretreatment has been shown to release tFA at levels that are deleterious to microbial activity [10]. However, there has been no systematic study of the release of $\mathrm{tFA}$ and related moieties during hydrothermal pretreatment of RS and RH. Nevertheless, Merali et al. [1, 14] demonstrated that hydrothermal pretreatment of wheat straw resulted in considerable degradation and solubilisation of arabinoxylans and decreases in the levels of cell wall-bound phenolic esters, including ferulates and diferulates, accompanied by loss of alkaline UV turquoise fluorescence of the cell wall residues. Therefore, it is highly likely that simple phenolics may be released from rice straw and husk by hydrothermal pretreatments.

The aim of the present study has been to employ analytical HPLC with diode array detection (DAD) $[14,15]$ to investigate the effect of hydrothermal pretreatment severity on the release of phenolic esters, diferulates, and related moieties from RH and RS, and to establish their levels in the pretreatment liquors.

\section{Results}

Fourier transform infrared (FTIR-ATR) spectroscopy of untreated and hydrothermally pretreated $\mathrm{RH}$ and $\mathrm{RS}$ solids

RS and RH were hydrothermally pretreated over a range of severities as described in the Methods. The pretreatment liquors were separated from the insoluble residues by centrifugation prior to analysis. General pretreatmentinduced changes in cell wall composition were evaluated using the FTIR-ATR spectra region from 1800 to $800 \mathrm{~cm}^{-1}$. Figure $1 \mathrm{a}, \mathrm{b}$ show spectra of $\mathrm{RH}$ and RS samples respectively; wavenumbers where pretreatment caused notable spectral changes are highlighted with vertical dashed lines. For both RH and RS, peaks at around 1740, 1630 and $1235 \mathrm{~cm}^{-1}$ decreased in intensity with increasing pretreatment severity. These $\mathrm{C}=\mathrm{O}$ stretching and $\mathrm{O}-\mathrm{H}$ bending bands relate to ester and acetyl groups of hemicellulosic polysaccharides which will have been hydrolysed and released from the residues, as shown for oilseed rape straw [16], wheat straw [3, 14, 17] and steam exploded RS and RH [18]. Associated with these losses was the increasing sharpness of carbohydrate peaks at wavenumbers around 1034, 1050, 1100 and $1155 \mathrm{~cm}^{-1}$ corresponding to the $\mathrm{C}-\mathrm{O} / \mathrm{C}-\mathrm{H}$ bond stretching in cellulose, and $\mathrm{C}-\mathrm{O}-\mathrm{C}$ stretching of $\beta-(1-4)$ linkages [19]. The FTIR spectra of the residues show a clear change from whole plant cell wall material towards increasingly pure lignocellulose and demonstrate the progressive removal of hemicelluloses. Lignin is mainly associated with peaks between $1600-1300 \mathrm{~cm}^{-1}$ and with increasing pretreatment severity, peaks became more pronounced at 1420 , 1505 and $1600-1620 \mathrm{~cm}^{-1}$. These bands are probably due to the stretching of aromatic lignin bonds, particularly $\mathrm{C}=\mathrm{O}$ and $\mathrm{C}=\mathrm{C}$ bonds [19]. These results are consistent with a relative increase in the amount of lignin present in the residue after pretreatment (Table 1a).

\section{Fluorescence microscopy of $\mathrm{RS}$ and $\mathrm{RH}$ residues}

The visual appearance of lignin and phenolic acids in the $\mathrm{RH}$ and RS (untreated and pretreated) was obtained using UV autofluorescence under neutral (Fig. 2a) and alkaline conditions (Fig. 2b). As Fig. 2a (1 and 2) shows, lignin and phenolic acids were all in blue under neutral condition and the levels of fluorescence were not significantly different between RH and RS samples. Under alkaline condition, $\mathrm{RH}$ was predominantly blue in colour (symptomatic of lignin) (Fig. 2b (1)) whilst RS was green/turquoise reflecting significant levels of cinnamic acid derivatives such as ferulic acid (tFA) [20] and relatively lower levels of lignin (Fig. 2b (2)) (see below). As pretreatment severity increased, the loss of fluorescence was observed under both neutral and alkaline condition (Fig. 2), suggesting the removal of lignin and phenolic acids after pretreatment.

\section{Quantification of Klason lignin in the solids of nontreated and pretreated RH and RS}

The content of Klason lignin in RH and RS was measured (Table 1). RH contains considerably more lignin than RS in untreated and pretreated samples. Table 1a shows 

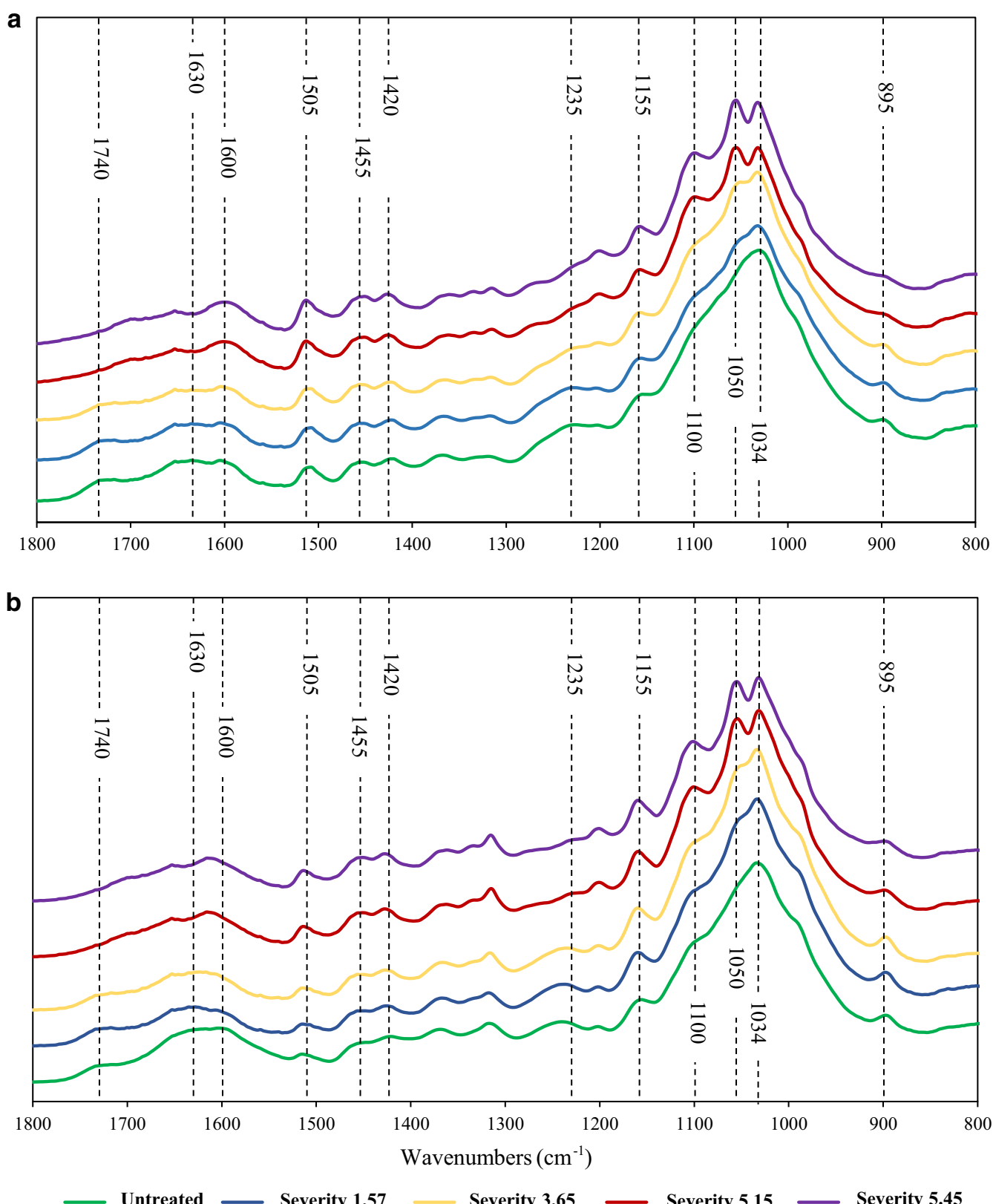

Fig. 1 FTIR spectra of RH and RS and of their insoluble residues after hydrothermal pretreatments at different severities. a RH; $\mathbf{b}$ RS. Colour codes for the spectra are given below the figures

increases of lignin content in residues of both $\mathrm{RH}$ and $\mathrm{RS}$ after pretreatment especially at higher severities. This is consistent with the hydrothermal release of hemicellulosic polysaccharides and volatile chemicals such as furfural as found in many other pretreatment studies [21, 22]. The concomitant increase in lignin is inconsistent with the pretreatment-related decline in fluorescence of the residues shown in Fig. 2 and suggests that fluorescent moieties, probably at the surface of the lignified material, had been lost disproportionately. Table $1 \mathrm{~b}$ shows that the lignin remaining in the residues, when presented as a function of the original raw material, is not significantly altered after hydrothermal pretreatments.

\section{Investigation of phenolic compounds in the liquors of pretreated samples}

Initial attempts to quantify tFA, diferulic acids (DiFA) and related phenolics that may have been released by 
Table 1 Klason lignin content (mg/g raw materials) in $\mathbf{R H}$ and $R S$ samples (UT and PT); $\mathbf{n = 3}$

\begin{tabular}{|c|c|c|c|c|}
\hline Severity & \multicolumn{2}{|c|}{ Rice husk } & \multicolumn{2}{|c|}{ Rice straw } \\
\hline \multicolumn{5}{|c|}{ a Lignin content (mg/g loaded materials) } \\
\hline 0.00 & 35.25 & \pm 1.23 & 22.01 & \pm 1.37 \\
\hline 1.57 & 36.18 & \pm 1.83 & 24.08 & \pm 0.82 \\
\hline 3.65 & 38.89 & \pm 1.90 & 26.48 & \pm 2.38 \\
\hline 5.15 & 45.57 & \pm 1.46 & 34.86 & \pm 2.92 \\
\hline 5.45 & 46.22 & \pm 0.85 & 36.73 & \pm 2.35 \\
\hline \multicolumn{5}{|c|}{ b Lignin content (mg/g raw materials) } \\
\hline 0.00 & 35.25 & \pm 1.23 & 22.10 & \pm 1.47 \\
\hline 1.57 & 34.89 & \pm 1.77 & 21.95 & \pm 0.76 \\
\hline 3.65 & 31.44 & \pm 1.59 & 22.17 & \pm 2.05 \\
\hline 5.15 & 34.36 & \pm 1.17 & 24.89 & \pm 2.63 \\
\hline 5.45 & 32.80 & \pm 0.67 & 23.61 & \pm 0.69 \\
\hline
\end{tabular}

a Shows lignin contents of the actual loaded biomass materials

b Shows lignin contents calculated on the basis of the original raw materials

hydrothermal pretreatment (severity 5.15), involved direct analysis of the pretreatment liquor by HPLC-DAD (Fig. 3a). Several large, unidentified early-running peaks
(A, B and C) were detected. However, the only free phenolics that could be identified from pure standards were protocatechuic aldehyde (pCald), $p$-OH-benzaldehyde ( $p$-OH-Bzald) and vanillin. To assess the presence of esterified phenolics, the pretreatment liquor was subjected to saponification (1 $\mathrm{M} \mathrm{NaOH})$ followed by liquidliquid extraction and HPLC [15]. The results (e.g. Fig. 3b) revealed a wide range of phenolics that could be separated by HPLC and identified from their retention times relative to the trans-cinnamic acid internal standard, and diode-array recorded spectra. Interestingly, saponification reduced the levels of early-running unidentified moieties in Fig. 3a (Unknown A, B and C peaks). Thus, it appears that the phenolics present in the pretreatment liquor were probably esterified to rapidly eluting fragments of polysaccharides that had been released by pretreatment-induced autohydrolysis. Hence, the saponification method was chosen for identification and comparative analysis of phenolic acids in the pretreatment liquors. After the investigation of liquors of pretreated samples, the phenolics remaining esterified to the hydrolysate solids were also extracted and assessed using the same approach [15].

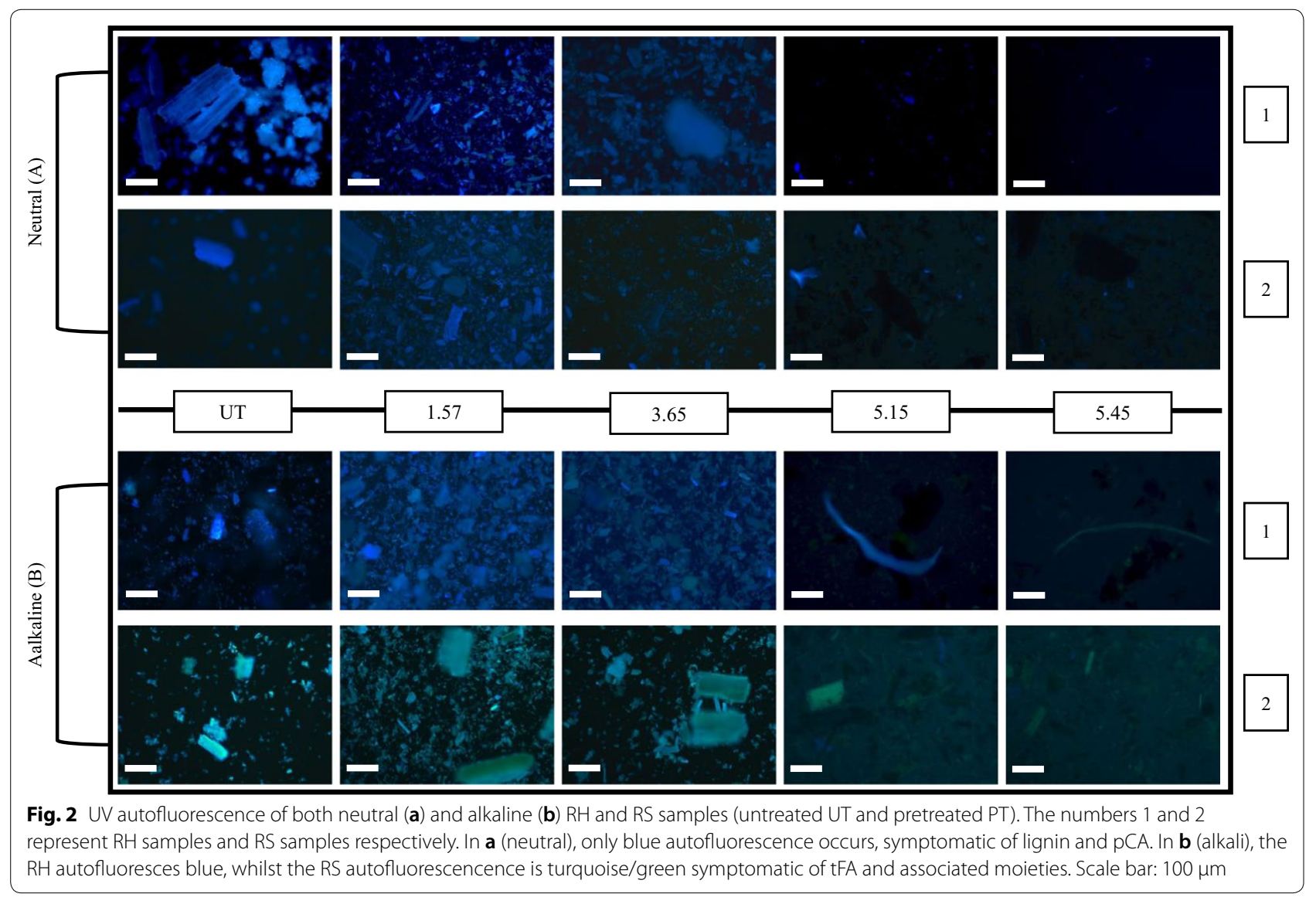




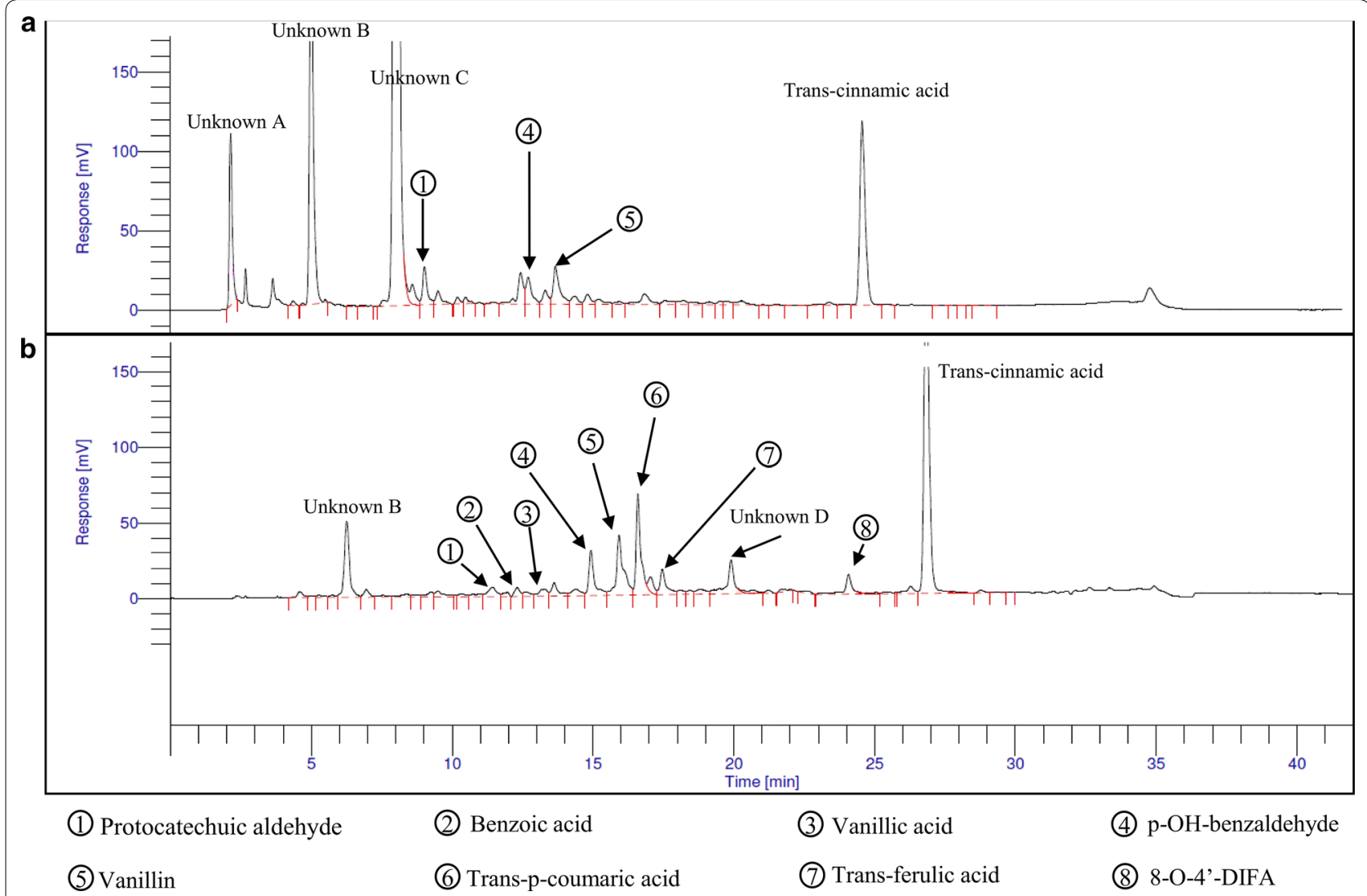

Fig. 3 HPLC chromatogram of phenolic compounds in RS pretreatment liquor produced at a severity of 5.15. a Direct injection of liquor showing the presence of only pCald, $p$-OH-Bzald and vanillin; $\mathbf{b}$ HPLC of moieties recovered by liquid-liquid extraction after saponification (showing a wide range of identified phenolics)

Comparison of total phenolics extracted from solids of $\mathrm{RH}$ and RS (untreated and pretreated) after saponification For extracting the phenolics from pretreated hydrolysate solids, preliminary studies showed that $4 \mathrm{Mol} \mathrm{NaOH}$ for $17 \mathrm{~h}$ was more effective for extracting phenolic esters than $1 \mathrm{Mol} \mathrm{NaOH}$ (Table 2) from raw RH and RS residues. However, for pretreated residues, 1 Mol was as effective. Therefore, to avoid unnecessary alkaline degradation, phenolics from the pretreated liquors and residues were saponified using $1 \mathrm{Mol} \mathrm{NaOH}$ for $17 \mathrm{~h}$ prior to acidification and liquid-liquid extraction.

\section{Phenolic compounds in the solids and liquors of raw and pretreated $\mathrm{RH}$ and RS}

In pretreated liquors and residues of RH and RS, 15 different phenolic compounds were identified and quantified including 12 phenolic acids, 2 aldehydes and 1 vanillin (Figs. 4, 5, 6). Total yields calculated for phenolics recovered from insoluble residues and the separated liquors after pretreatment at different severities are shown in Table 3. Total phenolics were similar in untreated RH and RS and in PTRH and PTRS pretreated at severity of
1.57. When severity was increased, the contents of phenolic compounds remaining in $\mathrm{RH}$ and $\mathrm{RS}$ residues were significantly reduced, and $\mathrm{RH}$ contained more total phenolics than RS in samples pretreated at severities of 3.65, 5.15 and 5.45 .

Identifiable ferulic acid moieties are presented in Fig. 4. tFA was present in considerably higher quantities in RS compared with RH. Pretreatment of both substrates resulted in little change in yields at the lower severities. However, at the higher severities, the levels of extractable tFA decreased by over $85 \%$. Interestingly, whilst a small quantity of (esterified) ferulic acid could be detected in the liquors, this was at relatively low levels. Small levels of cis-FA were detected, and these showed a decrease in the residues at higher pretreatments, but an increase in the liquors. Three diferulic acid moieties were also identified in untreated and pretreated RS and $\mathrm{RH}$ for the first time, released by saponification from both residues and liquors. The most abundant was 8-O-4'-DiFA, followed by $5,5^{\prime}$-DiFA and then $8,5^{\prime}$-DiFA. Generally, the DiFAs showed similar trends to tFA, in that larger quantities were present in the RS residues than those of $\mathrm{RH}$ and 
Table 2 Quantification of total phenolic compounds extracted from the solids of untreated and pretreated (severity 1.57) RH and RS

\begin{tabular}{|c|c|c|c|c|c|c|c|c|}
\hline \multirow[t]{3}{*}{ Severity } & \multicolumn{8}{|c|}{ Total (mono) phenolics (mg/g of raw materials) } \\
\hline & \multicolumn{4}{|c|}{ Rice husk } & \multicolumn{4}{|c|}{ Rice straw } \\
\hline & \multicolumn{2}{|c|}{$1 \mathrm{Mol} \mathrm{NaOH}$} & \multicolumn{2}{|c|}{$4 \mathrm{Mol} \mathrm{NaOH}$} & \multicolumn{2}{|c|}{$1 \mathrm{Mol} \mathrm{NaOH}$} & \multicolumn{2}{|c|}{$4 \mathrm{Mol} \mathrm{NaOH}$} \\
\hline Raw & 14.57 & \pm 0.57 & 15.82 & \pm 1.41 & 14.37 & \pm 0.45 & 17.20 & \pm 1.57 \\
\hline 1.57 & 15.90 & \pm 0.44 & 15.96 & \pm 1.21 & 16.23 & \pm 0.78 & 14.24 & \pm 0.83 \\
\hline
\end{tabular}

Untreated and pretreated samples were saponified with $1 \mathrm{Mol} \mathrm{NaOH}$ and $4 \mathrm{Mol} \mathrm{NaOH}$ separately before analysis by HPLC

Results were calculated as $\mathrm{mg} / \mathrm{g}$ of original lignocellulosic raw materials. $\mathrm{n}=3$

decreased from the residues at the higher pretreatment severities. Under these conditions, they increased in the pretreatment liquors and, unlike tFA, were maximum in the liquors obtained at higher severities suggesting a much higher degree of thermal stability.

In contrast to the ferulates above, all other simple phenolics extracted and quantified were, except for tFAderived truxillic acid (Fig. 5), present at higher levels in the RH and its liquors compared with RS. The most prominent of these was para-coumaric acid (pCA; Fig. 5) which was present at much higher levels than tFA generally. The levels of both pCA and tFA decreased in the residues as pretreatment severity increased. The other phenolics comprised truxillates (tFA- and pCA-derived), p-OH-benzoic acid, p-OH-phenyl acetic acid (Fig. 5), $p$-OH-benzaldehyde, protocatechuic aldehyde, vanillin and vanillic acid (Fig. 6). Interestingly, the levels of $p-\mathrm{OH}-$ $\mathrm{B}$, truxillic acid (FA-derived), PA, vanillin, $p$-OH-Bzald and pCald increased in both the pretreated $\mathrm{RH}$ and $\mathrm{RS}$ residues at the higher severities. It is possible that they are hydrothermally derived breakdown products from other wall phenolics, for example, those in lignin (hence the higher levels in RH). Recently, Rasmussen et al. [23] have shown that hydrothermal pretreatments can create a range of oligophenolic enzyme inhibitors from wheat straw lignocellulose.

\section{Discussion}

Lignin, lignin-derived phenolic compounds, hemicellulose and cellulosic saccharide breakdown products significantly reduce the efficiency of production of cellulosic bio-ethanol [24-26]. Several phenolic compounds have been reported to be released from lignocellulosic biomass during pretreatment including phenolic acids, tannins and gallic acid [27-29]. Other substantial research has highlighted the importance of lignins and lignin-derived phenolics in cell wall interpolymeric crosslinking (e.g. Sun et al. 2001). This study has extensively investigated the release and degradation of simple (esterified) cell wall phenolic compounds during hydrothermal pretreatment across a range of severities and has provided new information on the fate of diferulic acids.

Only recently has the inhibitory role of phenolic esters such as tFA and $p$-CA been considered seriously. Much of that work has focused on the free phenolic acids released after alkali pretreatments [10]. Such studies have demonstrated that ethanol producing strains of $E$. coli exhibit $\mathrm{IC}_{50}$ values of about $2.5 \mathrm{mM}$ each for free tFA and pCA. In the present study, no free tFA, pCA or diferulate phenolic acids were detected in the pretreatment liquors (Fig. 3). However, if the esterified phenolics present in the $\mathrm{RH}$ pretreatment liquors were to be de-esterified by esterases in the cellulase cocktails or by esterases released from the fermenting organisms, the resulting free $\mathrm{tFA}$ and $\mathrm{pCA}$ could reach concentrations of 0.12 and $0.9 \mathrm{mM}$, respectively-levels that would be significantly inhibitory to microbial fermenting organisms [10]. Currently, there is no information on their inhibitory functionality in the soluble, esterified forms, and further work will be needed to establish this. Also, there is no information currently on the potential inhibitory activity of the solubilised diferulate esters. Free diferulates may also be of significance in alkali pretreatment liquors.

After the lower severity pretreatments (which are in the commercial user range), significant levels of phenolic esters remain attached to cell wall polymers (Fig. 2). Whilst such moieties are unlikely to directly affect microbial activity, they may additionally function in inhibiting alcohol production. For example, the DiFAs create interpolymeric cross-links between arabinoxylan hemicelluloses. Phenolic esters are also known to cross-link polysaccharides with lignin $[30,31]$. Their presence is likely to attenuate hemicellulose disassembly and solubility during pretreatment and reduce subsequent diffusion of cellulases and hemicellulases into the wall matrix. Furthermore, some DiFAs have been strongly implicated in cell adhesion $[20,32,33]$ and may influence the rate and extent of cell separation in cereal residues during hydrothermal pretreatments as indicated previously [14]. This latter property is likely to affect the pretreatment-induced 


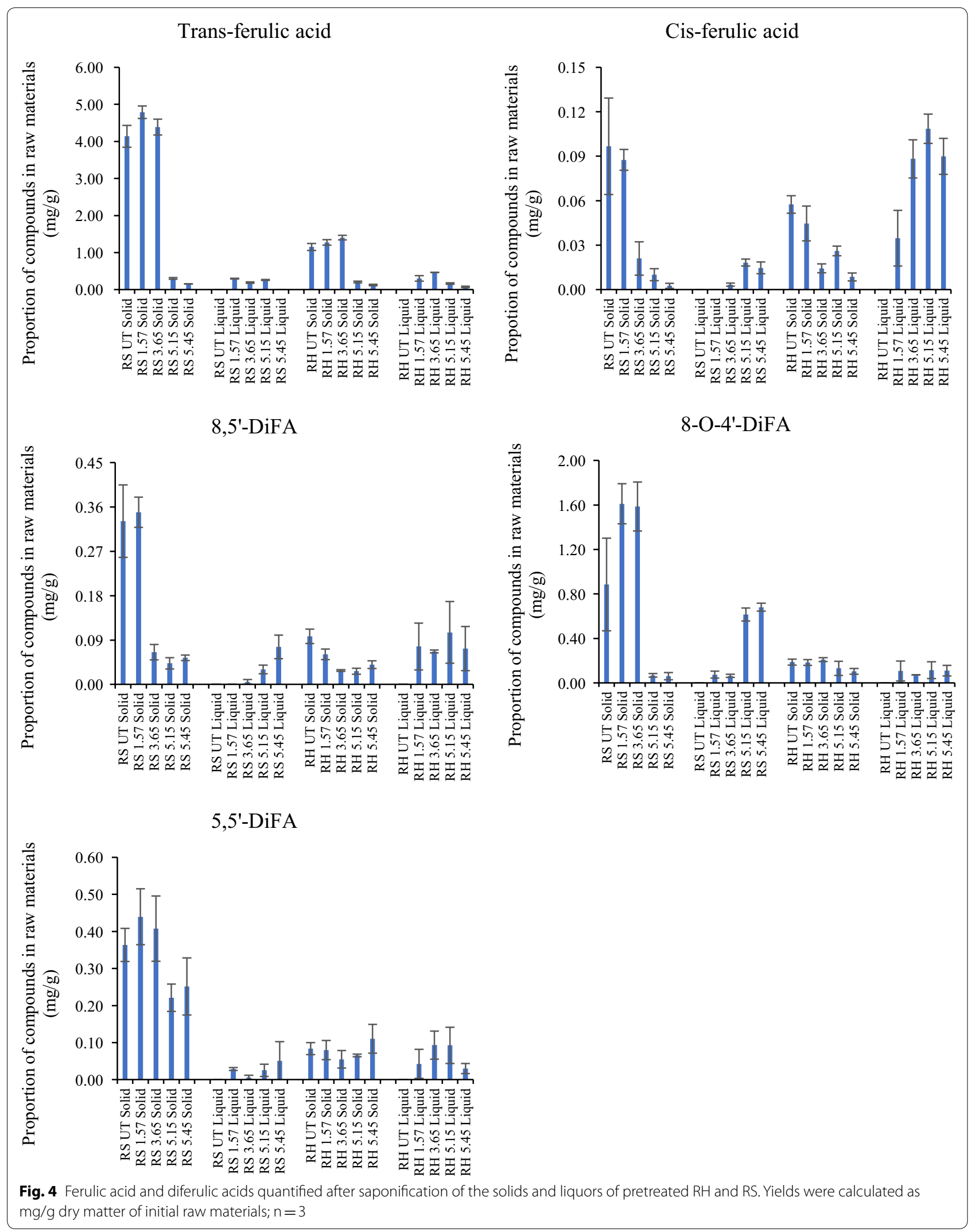




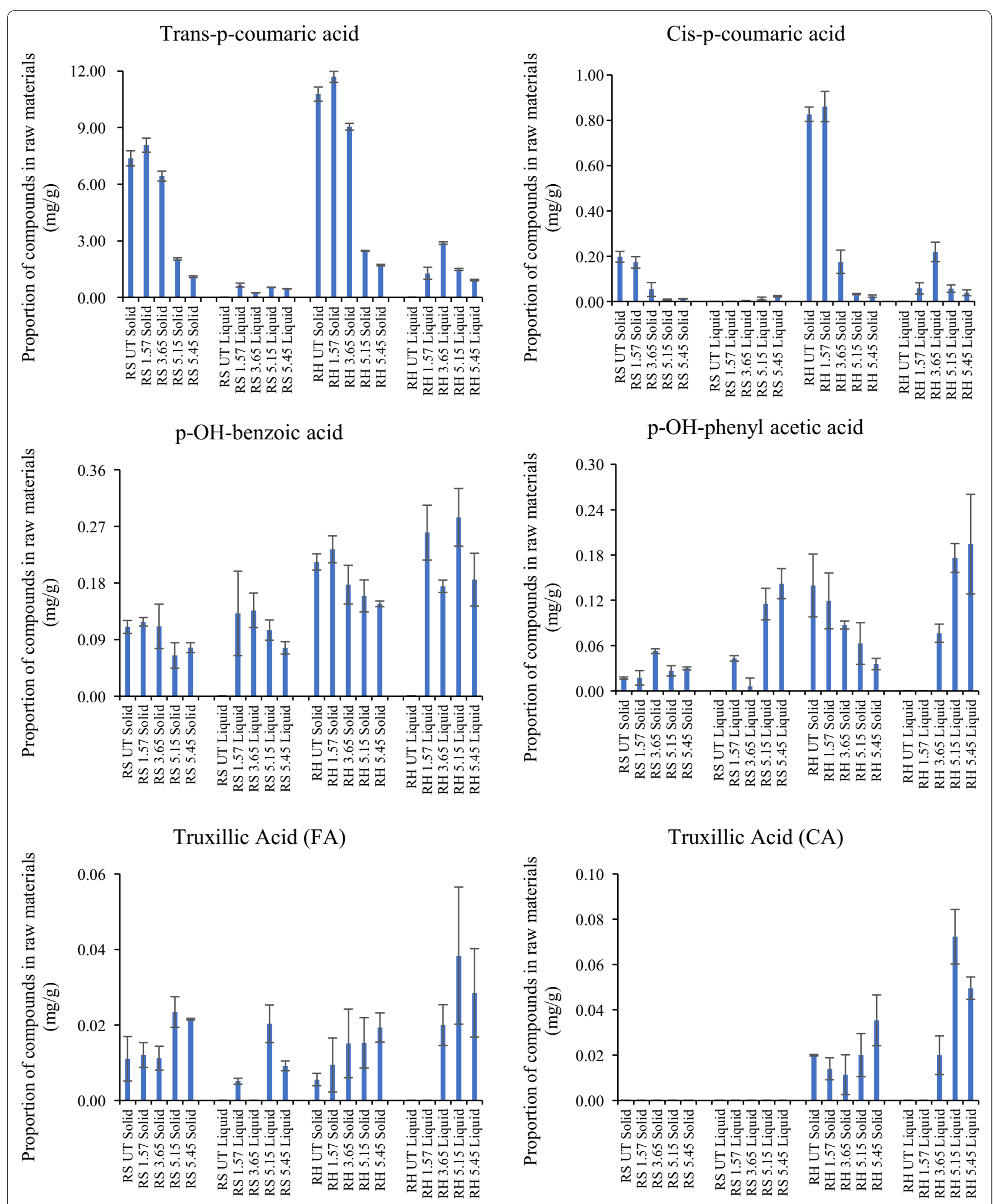

Fig. 5 Phenolic acids quantified after saponification of the solids and liquors of pretreated RH and RS. Yields were calculated as $\mathrm{mg} / \mathrm{g}$ of $\mathrm{dry}$ matter of initial raw materials; $n=3$ 


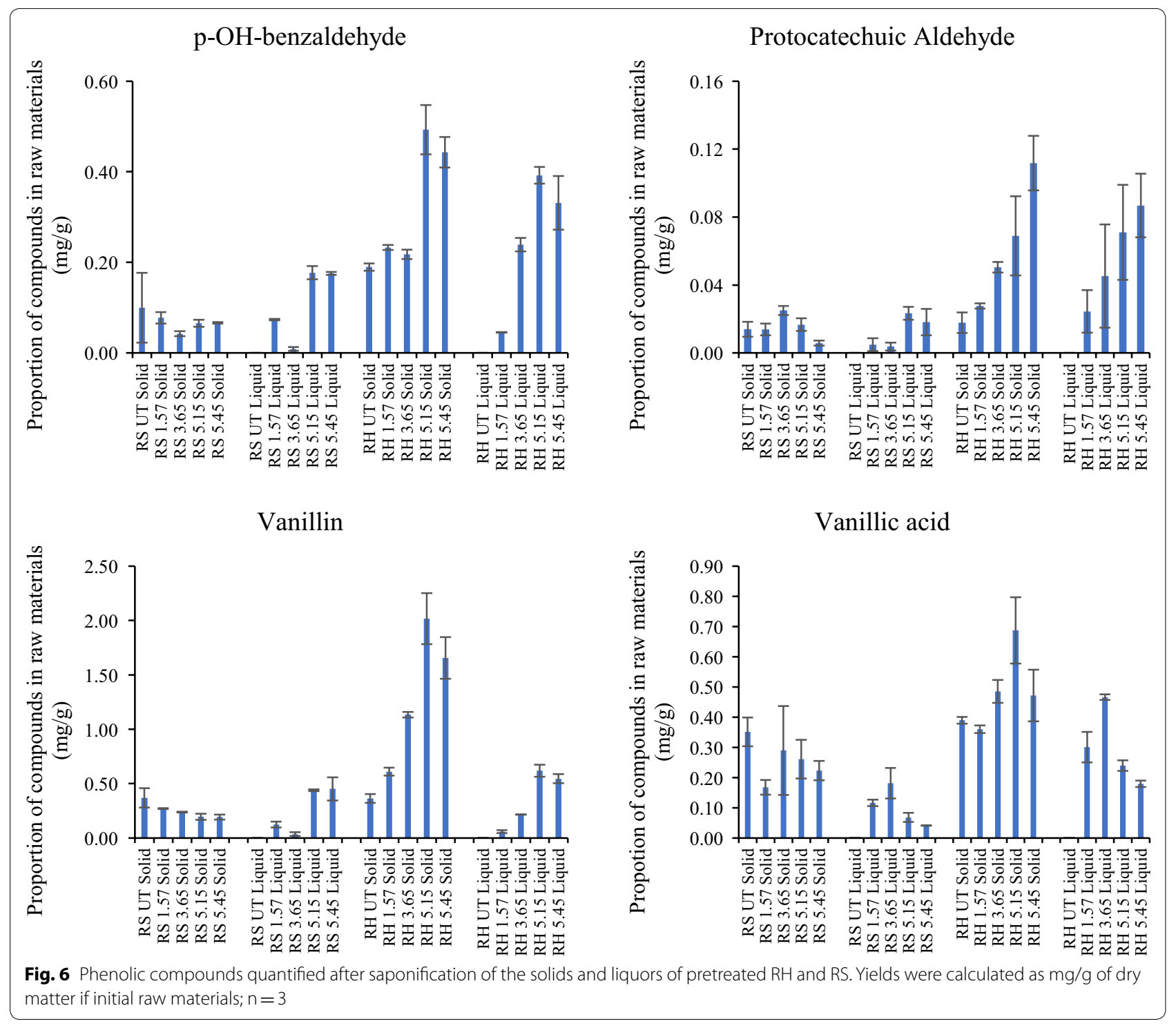

Table 3 Contents of total phenolic compounds in the solids and liquors of untreated and pretreated RH and RS

\begin{tabular}{|c|c|c|c|c|c|c|}
\hline \multirow[t]{3}{*}{ Severity } & \multicolumn{6}{|c|}{ Phenolic compounds (mg/g raw materials) } \\
\hline & \multicolumn{3}{|l|}{ RH } & \multicolumn{3}{|l|}{ RS } \\
\hline & Solids & Liquors & Total & Solids & Liquors & Total \\
\hline ut (4 M) & $15.82( \pm 1.27)$ & N/A & 15.82 & $17.20( \pm 1.57)$ & N/A & 17.20 \\
\hline 1.57 & $15.90( \pm 0.44)$ & $2.59( \pm 0.60)$ & 18.43 & $16.23( \pm 0.78)$ & $1.56( \pm 0.20)$ & 17.93 \\
\hline 3.65 & $13.13( \pm 0.28)$ & $5.14( \pm 0.15)$ & 18.28 & $13.73( \pm 0.65)$ & $0.91( \pm 0.05)$ & 14.93 \\
\hline 5.15 & $6.50( \pm 0.50)$ & $4.02( \pm 0.11)$ & 10.52 & $3.37( \pm 0.21)$ & $2.46( \pm 0.44)$ & 5.83 \\
\hline 5.45 & $5.07( \pm 0.43)$ & $2.94( \pm 0.24)$ & 8.01 & $2.27( \pm 0.20)$ & $2.22( \pm 0.09)$ & 4.49 \\
\hline
\end{tabular}

Results were calculated as $\mathrm{mg} / \mathrm{g}$ of raw materials. $\mathrm{n}=3$ 
increase in surface area-to-volume ratio of pretreated particulates. The levels of simple phenolics in RS and RH are also likely to have implications in relation to digestibility by ruminants. pCA had been reported to be associated with inhibitory activities reducing the digestibility of cell wall carbohydrates [34], and has been implicated as a toxin to microorganisms and a barrier to the digestion of materials during simulated rumen fermentation [35].

Finally, the majority of total phenolics from both $\mathrm{RH}$ and RS samples were degraded and lost after pretreatment at the higher severities. Such degradation of potential inhibitors may have a positive impact on saccharification and fermentation.

\section{Conclusion}

Hydrothermal pretreatment of $\mathrm{RH}$ and RS resulted in a decrease in hemicelluloses and a concomitant increase in the levels of cellulose and lignin. Simple phenolics such as tFA, diferulates and pCA were present in $\mathrm{RH}$ and RS; and were released, probably as esters of cell wall polysaccharide fragments, into the liquor during pretreatment, and degraded at the higher severities. Differences in lignin, tFA, DiFAs and pCA between RS and RH reflect differences in cell wall physiology and are probably responsible, in part, for the higher recalcitrance of $\mathrm{RH}$. The potential for pretreatment-liberated esterified phenolics to be inhibitory to fermenting microorganisms is not known. However, they are at concentrations that could be significantly inhibitory if released by enzyme activity. In addition, the release of other free phenolics such as vanillin, $p$-Cald, $p$-OH-B and $p-\mathrm{OH}$-Bzald during pretreatment may also reduce the efficiency of saccharification and fermentation.

\section{Materials and methodology Materials}

$\mathrm{RS}$ and $\mathrm{RH}$ of the same variety were sourced as described previously by Wood et al. [18].

\section{Milling of rice husk and rice straw}

$\mathrm{RH}$ and $\mathrm{RS}$ (prechopped into about $2 \mathrm{~cm}$ lengths) were milled into small particles $(<0.5 \mathrm{~mm})$ by using $\mathrm{RETSCH}$ cyclone mill (Retsch Limited, Hope Valley, United Kingdom). Milled materials were collected into plastic sample pots sealed with screw-caps and then stored under lab condition.

\section{Thermodynamic pretreatment of rice husk and rice straw}

Pretreatments of milled $\mathrm{RH}$ and RS were carried out using a BIOTAGE ${ }^{\circledR}$ Initiator and Reactor (Biotage AB, Uppsala, Sweden). Pretreatment severity was introduced and adapted from the research of Overend et al. [36].

$$
\text { Severity }(\mathrm{Ro})=\log _{10}\left(t \cdot \exp ^{\frac{T-100}{14.75}}\right)
$$

Severity was calculated from temperature and duration. Four different severities: $1.57\left(140{ }^{\circ} \mathrm{C}, 2.5 \mathrm{~min}\right), 3.65$ $\left(190{ }^{\circ} \mathrm{C}, 10 \mathrm{~min}\right), 5.15\left(200{ }^{\circ} \mathrm{C}, 160 \mathrm{~min}\right), 5.45\left(210{ }^{\circ} \mathrm{C}\right.$, $160 \mathrm{~min}$ ) were selected to pretreat milled $\mathrm{RH}$ and $\mathrm{RS}$ [37]. To give a 5\% (w/w) suspension, $750 \mathrm{mg}$ of each sample was transferred into $20 \mathrm{ml}$ microwave pressure tubes respectively and followed by the addition of $14.25 \mathrm{ml}$ distilled water. Those tubes were then capped and pretreated by using the Biotage reactor. After the pretreatment process, those tubes were cooled with compressed air to ambient and then stored in freezer $\left(-20^{\circ} \mathrm{C}\right)$.

\section{Fluorescence microscopy of pretreated and untreated RH and RS slurries}

Pretreated slurries (containing both liquids and solids) were defrosted and centrifuged. The supernatants were removed from pellets and transferred to $15-\mathrm{ml}$ plastic tubes for further investigation. For the neutral set, sample residues were re-suspended into distilled water, and for the alkaline set, samples of each residue were then treated with $1 \% \mathrm{NaOH}(\mathrm{w} / \mathrm{v})$ to establish an alkaline environment, and then autofluorescence was assessed immediately using an Olympus BX 60 fluorescence light microscope (Olympus, Tokyo, Japan) equipped with a Progress $\mathrm{C} 10^{\text {plus }}$ camera and software. Autofluorescence of each sample was recorded three times using a UV filter cube U-MWU, exciter filter BP330-385, and barrier filter BA 420.

\section{Fourier transform infrared (FT-IR) of pretreated and untreated $\mathrm{RH}$ and $\mathrm{RS}$ solids}

Pretreated solids of RH and RS were separated from liquors and oven-dried at $65{ }^{\circ} \mathrm{C}$ overnight. FT-IR spectra of each sample were collected using a BioRad FTS 175C Fourier transform infrared spectrometer (BioRad, Cambridge, MA, USA). Milled raw $\mathrm{RH}$ and $\mathrm{RS}$ and dried solids of pretreated $\mathrm{RH}$ and RS were placed in a Golden Gate $^{\mathrm{TM}}$ diamond-attenuated total reflectance (ATR) accessory (Specac, Slough, UK). Triplicates of each sample were scanned 100 times at a resolution of $2 \mathrm{~cm}^{-1}$ and the spectra were averaged and referenced against a spectrum of the empty crystal. The spectra were collected in the region of $4000-800 \mathrm{~cm}^{-1}$, were truncated to $1800-$ $800 \mathrm{~cm}^{-1}$ and area normalised for analysis.

\section{Klason lignin analysis of pretreated rice husk and rice straw} Pretreated slurries (containing both liquids and solids) of $\mathrm{RH}$ and RS were oven-dried at $65^{\circ} \mathrm{C}$ overnight, and then $100 \mathrm{mg}$ of each sample was loaded into 25-ml Sovirel 
culture tubes (The Science Company, 7625 W Hampden Ave, Unit 14, Lakewood, Colorado, US). The hydrolysis procedure was started at room temperature with the additions of $1.5 \mathrm{ml}$ sulphuric acid. After 3-h incubation, $18 \mathrm{ml}$ distilled water was added to each tube, and they were incubated at $100{ }^{\circ} \mathrm{C}$ for $2.5 \mathrm{~h}$. Hydrolysates of $\mathrm{RH}$ and RS were then transferred into pre-weighed sintered glass funnels (WT funnels) with porosity four (VWR International Ltd, 1151 Budapest, Szövőgyár utca 11-13, Hungary) and then washed with distilled water until the acid was completely removed. The funnels containing the residues were dried at $50{ }^{\circ} \mathrm{C}$ overnight and weighed, then placed into a Vulcan PD Furnace 3-550 (Dentsply Sirona Global Headquarters, Susquehanna Commerce Center. 221 West Philadephia Street, Suite 60 W, York PA, USA) and incinerated at $500{ }^{\circ} \mathrm{C}$ for $22 \mathrm{~h}$. The weights of funnels containing ash were recorded (WT funnels and ash). Samples for lignin analysis were prepared as triplicates. Final lignin contents of samples were calculated using the following equation:

$$
\begin{aligned}
\text { Lignin } & =\text { WT funnels and hydrolysates } \\
& - \text { WT funnels and ash }(\mathrm{mg} / \mathrm{g} \text { Raw materials }) .
\end{aligned}
$$

\section{Analysis of phenolic compounds in untreated and pretreated RH and RS solids}

Liquors of pretreated $\mathrm{RH}$ and RS were transferred into tubes and stored at $-20^{\circ} \mathrm{C}$ for analysis. Solids were dried at $65{ }^{\circ} \mathrm{C}$ overnight and $5 \mathrm{mg}$ of each sample was loaded into Sovirel tubes. Saponification was carried out by addition of $4 \mathrm{ml} 1 \mathrm{M} \mathrm{NaOH}$ (de-oxygenated with nitrogen). After de-oxygenating by over-flushing nitrogen, the tubes were capped with screw caps and placed in the dark on a rotating sample mixer for $21 \mathrm{~h}$. At the end of this period the samples were neutralised and acidified by adding $1.5 \mathrm{ml}$ distilled water and $0.5 \mathrm{ml}$ of concentrated HCL (37\% w/v). Trans-cinnamic acid $(0.2 \mathrm{mg} /$ $\mathrm{ml}$, dissolved in 1:1 Methanol-water mixture) was used as internal standard and $50 \mu \mathrm{l}$ was added into each sample. Liquid-liquid extraction of phenolic acids from the acidified solution was carried out by using ethyl-acetate (three times). Following the evaporation of ethyl-acetate, phenolic acids were re-dissolved in $1 \mathrm{ml}$ methanol-water mixture. Phenolic acids were analysed and quantified by using HPLC (High-Performance Liquid Chromatography) using a Perkin-Elmer series 200 LC Pump, PerkinElmer advanced LC Processor ISS200, Phenomenex Column Luna $5 \mu \mathrm{C} 18$ (2), 250*4.6 mm equipped with precolumn and Perkin Elmer Diode Array UV Detector (Waltham, Massachusetts, USA) [15]. Phenolic compounds were initially identified by their relative retention time and then further compared to identical chromatography spectrum of individual phenolic compounds. The method for identifying phenolics was adapted from the study of Waldron [38].

Solids of untreated and samples pretreated at severity 1.57 were saponified as above but using $4 \mathrm{M} \mathrm{NaOH}$. Samples were analysed in triplicate.

\section{Phenolic compounds analysis of liquors of pretreated RH and RS}

Method A (direct injection): $50 \mu \mathrm{l}$ of $0.2 \mathrm{mg} / \mathrm{ml}$ internal standard (trans-cinnamic acid) was added to a sample tube containing $95 \mu \mathrm{l}$ of liquor and then $855 \mu \mathrm{l}$ of methanol $(50 \% \mathrm{v} / \mathrm{v})$ was added to give a total volume of $1 \mathrm{ml}$. This was injected directly onto the HPLC-DAD.

Method B: Saponification and liquid-liquid extraction. This followed the method for extracting and analysing esterified phenolic acids of pretreated solids (above). The same method and HPLC was used for the quantification of phenolic acids.

Samples were all prepared and processed as triplicates.

\section{Abbreviations}

$\mathrm{RH}$ : rice husk; RS: rice straw; PTRH: pretreated rice husk; PTRS: pretreated rice straw; HPLC: high-performance liquid chromatography; tFA: trans-ferulic acid; pCA: para-coumaric acid; DiFA: diferulic acid; 5HMF: hydroxymethalfurfural; 2FA: furfural; pCald: protocatechuic aldehyde; VA: vanillic acid; $p-\mathrm{OH}-\mathrm{B}: p-\mathrm{OH}-$ benzoic acid; DAD: diode array detection; FTIR-ATR: fourier transform infraredattenuated total reflectance.

\section{Authors' contributions}

JW, JD, SRAC, INR and KWW: conceived the study design and edited the manuscript. AE, SRAC and NW helped to complete the experiment design and suggested improvements to the methodology. JW: carried out the majority of the laboratory work, produced the initial results dataset and drafted the manuscript. SRAC: helped with HPLC set up, operation and data collection. All authors read and approved the final manuscript.

\section{Author details}

${ }^{1}$ The Biorefinery Centre, Quadram Institute Bioscience, Norwich Research Park, Colney, Norwich NR4 7UA, UK. ${ }^{2}$ Quadram Institute Bioscience, Norwich Research Park, Colney, Norwich NR4 7UA, UK. ${ }^{3}$ The National Collection of Yeast Cultures, Quadram Institute Bioscience, Norwich Research Park, Colney, Norwich NR4 7UA, UK.

\section{Competing interests}

The authors confirm that they have no competing interests concerning the content and publication of the manuscript.

Availability of data and materials

All appropriate data for this study has been included in the manuscript.

Ethics approval and consent to participate

Not applicable.

\section{Funding}

JW was self-funded to undertake this study as part of his PhD. This work was supported by the BBSRC Institute Strategic Programme "Food and Health" Grant No. BB/J004545/1 and BBSRC Grant No. BB/J013838/1.

\section{Publisher's Note}

Springer Nature remains neutral with regard to jurisdictional claims in published maps and institutional affiliations. 
Received: 17 February 2018 Accepted: 30 May 2018

Published online: 11 June 2018

\section{References}

1. Merali Z, Marjamaa K, Kasper A, Kruus K, Gunning AP, Morris VJ, Waldron KW. Chemical characterization of hydrothermally pretreated and enzyme-digested wheat straw: an evaluation of recalcitrance. Food Chem. 2016;198:132-40.

2. Arshadi M, Attard TM, Lukasik RM, Brncic M, Lopes AMD, Finell M, Geladi P, Gerschenson LN, Gogus F, Herrero M, et al. Pre-treatment and extraction techniques for recovery of added value compounds from wastes throughout the agri-food chain. Green Chem. 2016;18(23):6160-204.

3. Auxenfans T, Cronier D, Chabbert B, Paes G. Understanding the structural and chemical changes of plant biomass following steam explosion pretreatment. Biotechnol Biofuels. 2017;10:36.

4. Palmqvist E, Hahn-Hagerdal B. Fermentation of lignocellulosic hydrolysates. I: inhibition and detoxification. Bioresour Technol. 2000;74(1):17-24

5. Palmqvist E, Hahn-Hägerdal B. Fermentation of lignocellulosic hydrolysates. II: inhibitors and mechanisms of inhibition. Bioresour Technol. 2000;74(1):25-33.

6. Wood IP, Cao H-G, Tran L, Cook N, Ryden P, Wilson DR, Moates GK, Collins SRA, Elliston A, Waldron KW. Comparison of saccharification and fermentation of steam exploded rice straw and rice husk. Biotechnol Biofuels. 2016;9(1):193

7. González-Bautista E, Santana-Morales JC, Ríos-Fránquez FJ, Poggi-Varaldo HM, Ramos-Valdivia AC, Cristiani-Urbina E, Ponce-Noyola T. Phenolic compounds inhibit cellulase and xylanase activities of Cellulomonas flavigena PR-22 during saccharification of sugarcane bagasse. Fuel. 2017;196(Supplement C):32-5.

8. Kellock M, Rahikainen J, Marjamaa K, Kruus K. Lignin-derived inhibition of monocomponent cellulases and a xylanase in the hydrolysis of lignocellulosics. Bioresour Technol. 2017:232(Supplement C):183-91.

9. Xiao B, Sun XF, Sun R. Chemical, structural, and thermal characterizations of alkali-soluble lignins and hemicelluloses, and cellulose from maize stems, rye straw, and rice straw. Polym Degrad Stab. 2001;74(2):307-19.

10. Hou JJ, Ding C, Qiu Z, Zhang QZ, Xiang WN. Inhibition efficiency evaluation of lignocellulose-derived compounds for bioethanol production. J Clean Prod. 2017:165:1107-14.

11. Zhang QZ, Huang HQ, Han H, Qiu Z, Achal V. Stimulatory effect of in situ detoxification on bioethanol production by rice straw. Energy. 2017;135:32-9

12. Soares LCSR, Chandel AK, Pagnocca FC, Gaikwad SC, Rai M, da Silva SS Screening of yeasts for selection of potential strains and their utilization for in situ microbial detoxification (ISMD) of sugarcane bagasse hemicellulosic hydrolysate. Indian J Microbiol. 2016;56(2):172-81.

13. Sato TK, Liu TJ, Parreiras LS, Williams DL, Wohlbach DJ, Bice BD, Ong IM, Breuer RJ, Qin L, Busalacchi D, et al. Harnessing genetic diversity in Saccharomyces cerevisiae for fermentation of xylose in hydrolysates of alkaline hydrogen peroxide-pretreated biomass. Appl Environ Microbiol. 2014;80(2):540-54.

14. Merali Z, Ho JD, Collins SRA, Le Gall G, Elliston A, Kasper A, Waldron KW. Characterization of cell wall components of wheat straw following hydrothermal pretreatment and fractionation. Bioresour Technol. 2013;131:226-34

15. Waldron KW, Parr AJ, Ng A, Ralph J. Cell wall esterified phenolic dimers: identification and quantification by reverse phase high performance liquid chromatography and diode array detection. Phytochem Anal. 1996;7(6):305-12.

16. Ryden P, Gautier A, Wellner N, Tapp HS, Horn SJ, Eijsink VGH, Waldron KW. Changes in the composition of the main polysaccharide groups of oil seed rape straw following steam explosion and saccharification. Biomass Bioenergy. 2014;61:121-30.

17. Collins SRA, Wellner N, Bordonado IM, Harper AL, Miller CN, Bancroft I, Waldron KW. Variation in the chemical composition of wheat straw: the role of tissue ratio and composition. Biotechnol Biofuels. 2014;7:121.
18. Wood IP, Cao HG, Tran L, Cook N, Ryden P, Wilson DR, Moates GK, Collins SRA, Elliston A, Waldron KW. Comparison of saccharification and fermentation of steam exploded rice straw and rice husk. Biotechnol Biofuels. 2016;9:193.

19. Schwanninger M, Rodrigues JC, Pereira H, Hinterstoisser B. Effects of short-time vibratory ball milling on the shape of FT-IR spectra of wood and cellulose. Vib Spectrosc. 2004;36(1):23-40.

20. Parker ML, Waldron KW. Texture of Chinese water chestnut-involvement of cell-wall phenolics. J Sci Food Agric. 1995:68(3):337-46.

21. Kristensen JB, Thygesen LG, Felby C, Jørgensen H, Elder T. Cell-wall structural changes in wheat straw pretreated for bioethanol production. Biotechnol Biofuels. 2008;1 (1):5.

22. Jönsson LJ, Alriksson B, Nilvebrant N-O. Bioconversion of lignocellulose: inhibitors and detoxification. Biotechnol Biofuels. 2013:6(1):16.

23. Rasmussen H, Tanner D, Sorensen HR, Meyer AS. New degradation compounds from lignocellulosic biomass pretreatment: routes for formation of potent oligophenolic enzyme inhibitors. Green Chem. 2017:19(2):464-73.

24. Zeng Y, Zhao S, Yang S, Ding S-Y. Lignin plays a negative role in the biochemical process for producing lignocellulosic biofuels. Curr Opin Biotechnol. 2014;27(Supplement C):38-45.

25. Taherzadeh M, Karimi K. Pretreatment of lignocellulosic wastes to improve ethanol and biogas production: a review. Int J Mol Sci. 2008:9(9):1621.

26. Cho DH, Lee YJ, Um Y, Sang B-I, Kim YH. Detoxification of model phenolic compounds in lignocellulosic hydrolysates with peroxidase for butanol production from Clostridium beijerinckii. Appl Microbiol Biotechnol. 2009;83(6):1035-43.

27. Panagiotou $G$, Olsson L. Effect of compounds released during pretreatment of wheat straw on microbial growth and enzymatic hydrolysis rates. Biotechnol Bioeng. 2007:96(2):250-8.

28. Ximenes E, Kim Y, Mosier N, Dien B, Ladisch M. Deactivation of cellulases by phenols. Enzyme Microb Technol. 2011;48(1):54-60.

29. Chen S-F, Mowery RA, Scarlata CJ, Chambliss CK. Compositional analysis of water-soluble materials in corn stover. J Agric Food Chem. 2007:55(15):5912-8

30. Ralph J, Grabber JH, Hatfield RD. Lignin-ferulate cross-links in grassesactive incorporation of ferulate polysaccharide esters into ryegrass lignins. Carbohyd Res. 1995;275(1):167-78.

31. Bunzel M, Ralph J, Lu F, Hatfield RD, Steinhart H. Lignins and ferulateconiferyl alcohol cross-coupling products in cereal grains. J Agric Food Chem. 2004:52(21):6496-502

32. Parker CC, Parker ML, Smith AC, Waldron KW. Thermal stability of texture in chinese water chestnut may be dependent on $8,8^{\prime}$-diferulic acid (aryltetralyn form). J Agric Food Chem. 2003;51 (7):2034-9.

33. Waldron KW, Smith AC, Parr AJ, Ng A, Parker ML. New approaches to understanding and controlling cell separation in relation to fruit and vegetable texture. Trends Food Sci Technol. 1997;8(7):213-21.

34. Taboada A, Novo-Uzal E, Flores G, Loureda M, Ros Barceló A, Masa A Pomar F. Digestibility of silages in relation to their hydroxycinnamic acid content and lignin composition. J Sci Food Agric. 2010;90(7):1155-62.

35. Theodorou MK, Gascoyne DJ, Akin DE, Hartley RD. Effect of phenolic acids and phenolics from plant cell walls on rumenlike fermentation in consecutive batch culture. Appl Environ Microbiol. 1987;53(5):1046-50.

36. Overend RP, Chornet E, Gascoigne JA. Fractionation of lignocellulosics by steam-aqueous pretreatments [and discussion]. Philos Trans R Soc Lond A Math Phys Sci. 1987;321(1561):523-36.

37. Wu J, Elliston A, Le Gall G, Colquhoun IJ, Collins SRA, Wood IP, Dicks J, Roberts IN, Waldron KW. Optimising conditions for bioethanol production from rice husk and rice straw: effects of pre-treatment on liquor composition and fermentation inhibitors. Biotechnol Biofuels. 2018;11(1):62.

38. Waldron KW. Cell wall esterified phenolic dimers: identification and quantification by reverse phase high performance liquid chromatography and diode array detection. Phytochem Anal. 1996:7:305-12. 